\title{
Artificial antibodies for troponin T by its imprinting on the surface of multiwalledcarbon nanotubes: Its use as sensory surfaces
}

Felismina T.C. Moreira, Rosa A.F. Dutra, João P.C. Noronha, Alexandre L. Cunha, M. Goreti F. Sales

\section{ABSTRACT}

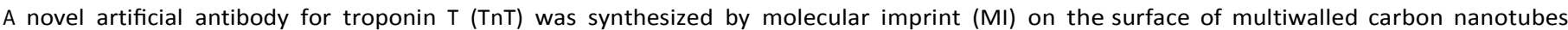

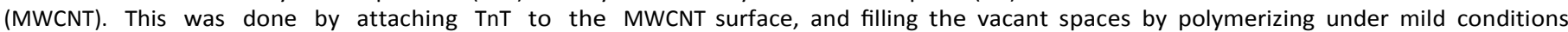

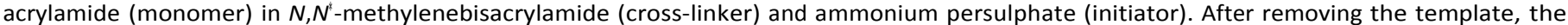

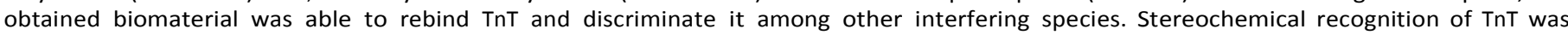

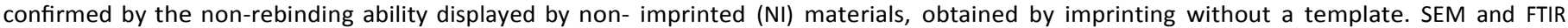

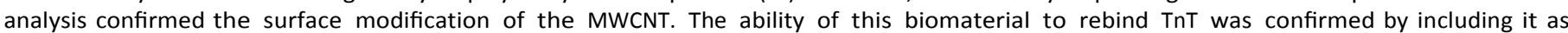

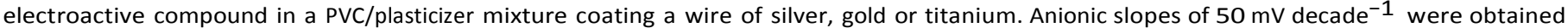

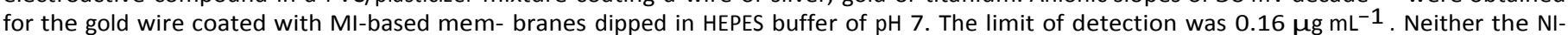

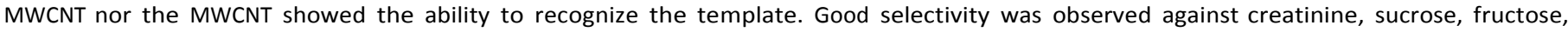

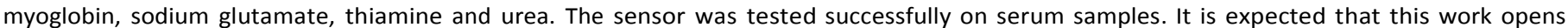
new horizons on the design of new artificial antibodies for complex protein structures.
\end{abstract}

Keywords: Artificial antibody, ,troponin T, Molecularly imprinted biomaterials, Potentiometric sensor, Cardiac biomarker

\section{Introduction}

Cardiovascular diseases are top-killer chronic diseases (McDonnell et al., 2009), accounting for more than half of the deaths in the western world. Reducing the mortality of acute events, as well as subsequent collateral damage, is imperative andrequires an immediate diagnostic of the patient condition. This relies on the clinical history of the patient, electrocardiogram, phys- ical examination and biochemical tests regarding specific cardiac biomarkers (Morrow, 2006), substances that are released into the blood when the heart is damaged (http://www.medscape.com). The use of biomarkers has increased continuously over time (Eriksson et al., 2006) for increasing the diagnostic accuracy and helping managing patients with a minimally invasive procedure.
Several cardiac biomarkers have been identified for myocar- dial injury/necrosis. Those of higher sensitivity and specificity are cardiac troponins (Takeuchi and Hishiya, 2008). Cardiac troponins consist of a complex of troponin C (TnC), troponin I (TnI) and TnT that regulates the contraction of striated and cardiac muscle by controlling the calciummodulated interaction between actin and myosin. Both TnT and TnI

are recommended markers of choice in the evaluation of acute coronary syndrome ( $\mathrm{TnC}$ is unspecific). These are measured in the blood, where the complex usually dis- sociates with time into free cTnT and I/C complex (Kemp et al., 2004). The effective pattern of cTnl complex released from the tis- sue is however affected by the degree of ischaemia or reperfusion experienced by the damaged myocytes. Furthermore, cTnlin blood is liable to proteolytic degradation (Kemp et al., 2004). Thus, the existence of multiple forms of cTnl and its small stability pose seri- ous difficulties on the development of new analytical procedures. Assays on TnT seem much more reliable and of wider application. Current techniques to determine $\mathrm{TnT}$ rely on immune/antigen reactions that are very selective but of small stability, high price, and long runs. They are not portable and require long time for a 
response that is not always accurate. They are also too expensive for wide screening programs or routine measurements inside hos- pitals, mostly because they rely on natural antibodies. These include enzyme linked immunosorbent assay (ELISA) (Katus et al., 1989), radioimmunoassay (RIA) (Cummins et al., 1987), immunochromatographic (Penttil et al., 1999) tests, electrochemiluminescence immunoassay (Klein et al., 1998), and surface plasmon resonance (SPR) (Dutra and Kubota, 2007; Dutra et al., 2007). Alterna- tive methods employ highly sophisticated separative procedures (Cavaliere et al., 2008; Labugger et al., 2003; Risnik et al., 1985) that are of high cost and unsuitable to carry out on-site analysis (at least outside central hospitals). Overall, these constraints may be avoided by replacing the natural antibodies by their synthetic coun- terparts and employing these materials on a suitable transducer interface.

Plastic antibodies may be prepared by means of molecular imprinting (MI) techniques, using inexpensive reagents and offer-ing stable and reproducible materials of quick response (<30 s) (Thygesen et al., 2010). $\mathrm{MI}$ is the 3-D or 2-D imprint of a certain molecule in a rigid polymeric matrix build typically with synthetic materials made from vinyl functional derivatives. The template molecule is later removed without disturbing the geometry of the solid matrix. The molecularly imprinted polymer (MIP) keeps the ability to rebind the template because of its functional arrange-ment regarding shape selectivity and preorganization of functionalgroups (May and Wang, 2008; Simon et al., 2007).

Traditional bulk imprinting of proteins has been proven difficult (Turner et al., 2006). The main drawbacks include reduced mass transfer and permanent entrapment of the macromolecule tem- plate in the polymer matrix, diminished integrity of the polymer structure, restricted solvent selection, and production of hetero- geneous binding sites (Bossi et al., 2001; Ramanaviciene and Ramanavicius, 2004). This hindered performance is avoided by sur- face imprinting. In surface imprinting, molecules with nanoscale dimensions can be assembled on a surface, piece by piece, with high structural control, mimicking nature's modular approach to nanostructured materials. Eventually, most of the imprinted sites are near or in the surface, with most templates being removed from the highly cross-linked matrix. Template rebind produces electri- cal, optical, thermal or mass changes in the nanostructured surface, thus enabling its detection.

Searching for a high number of effective imprinted sites, the plastic antibodies may be designed on top of nanostructured materials. Their small dimension leads to extremely high surface- tovolume ratio, favoring miniaturization (Agasti et al., 2010), and to a more homogeneous distribution of the recognition sites (Guan et al., 2008). The use of multiwalled carbon nanotubes (MWCNTs) for this purpose is a possibility, offering many advantages. They display one hundred times the tensile strength of steel, excellent thermal conductivity and electrical conductivity similar to copper but with the ability to carry much higher currents (Merkoc, 2006). Transducers of different metals (optical, electrical, mass or ther- mal) may be applied to recognize the interaction between $\mathrm{TnT}$ and its plastic antibody attached to MWCNT. Considering specifically that this is intended for diagnosis in point-of care, portability, low cost, high selectivity and small size are required features. This may be achieved by potentiometric readings with PVC-based sensory surfaces (Bakker and Telting-Diaz, 2002; Bakker, 2004; Bakker and Qin, 2006; Bobacka et al., 2008), employing the plastic antibod- ies as electroactive materials. The selectivity is achieved bydoping the membranes with MI particles that, in principal, may act as neutral or charged ionophores that selectively and reversibly bind $\mathrm{TnT}$. A potential difference is established across the membrane by the transfer of the ionized analyte across the interface between the aqueous solution and membrane phase. Nernstian responses are obtained when the primary ion is the only major ion that is selectively transferred across the interface between the two phases (Amemiya, 2007).

Thus, the design of new MI materials interacting selectively with TnT on the surface of MWCNT and subsequent potentiometric transduction are presented. TnT is linked to the surface of carboxylated MWCNTs. Then, acrylamide (AAM, functional monomer),

$\mathrm{N}, \mathrm{N}^{*}$-methylenebisacrylamide (NNMBA, cross-linker) and ammo-

nium persulphate (APS, initiator) are reacted under mild conditions to create a rigid structure around the template. Then, the template is removed by chemical treatment. A similar procedure was car- ried out without template ( $\mathrm{TnT}$ ) and considered as non-imprinted (NI) control (Jiang et al., 2004). These biomaterials are employed as electroactive materials for potentiometric transduction.

\section{Experimental}

\subsection{Apparatus}

All potential measurements were made by a Crison, GLP $21 \mathrm{pH}$ meter ( $\pm 0.1 \mathrm{mV}$ sensitivity), at room temperature, and under con- stant stirring. The output signal was received by a commutation unit leading to one of six ways out, enabling the simultaneous reading of 6 ISEs. The reference electrode was of $\mathrm{Ag} / \mathrm{AgCl}$ and

was prepared by dipping the silver wire in a $5 \times 10^{-3} \mathrm{~mol} \mathrm{~L}^{-1}$ $\mathrm{FeCl}_{3}$ solution. The assembly of the potentiometric cell was as follows: metal|TnT selective membrane|buffered sample solution $\left(1 \times 10^{-3} \mathrm{~mol}\right.$ $\mathrm{L}^{-1}$ HEPES, $\mathrm{pH}$ 7) $\mid \mathrm{Ag} / \mathrm{AgCl}$ reference.

Infrared spectra were collected by a Nicolet 6700 FTIR spectrom- eter coupled to an ATR (Attenuated Total Reflectance) sampling accessory of diamond contact crystal from Nicolet. A scanning electron microscope (SEM) with X-ray microanalysis, JEOL JSM 35C/Noran Voyager, was used.

\subsection{Reagents}

All chemicals were of analytical grade and de-ionized water (conductivity $<0.1 \mu \mathrm{S} / \mathrm{cm}$ ) was employed throughout. Carboxylated MWCNTs were bought from Dropsens, Spain. TnT, 4-(2hydroxyethyl)-1-piperazineethanesulfonic acid (HEPES), piperazine- $N, N^{*}$-bis(2-ethanesulfonic acid) (PIPES), onitrophenyloctyl (ONPOE), poly(vinyl chloride) high molecular weight (PVC), acrylamide (AAM), N,N-methylenebisacrylamide (NNMBA), ammonium persulphate (APS), oxalic acid (Oac), $N$ hydroxysuccinimide (NHS), $N$-ethyl- $N^{*}$-(3-dimethylaminopropyl) carbodiimide hydrochloride (EDAC), and sodium chloride ( $\mathrm{NaCl}$ ) were purchased from Fluka. Tetrahydrofuran (THF) was obtained from RiedeldeHäen.

\subsection{Synthesis of biomimetic materials}

\subsubsection{Activation of the carboxylic acid in the MWCNT}

About $3.0 \mathrm{mg}$ of carboxylated MWCNTs were suspended in $1.0 \mathrm{ml}$ of deionized water by sonicating the mixture for about 1 $\mathrm{min}$. Then, $1.0 \mathrm{ml}$ of an aqueous solution containing $5 \mathrm{mmol} \mathrm{L}^{-1}$ NHS and $2 \mathrm{mmol} \mathrm{L}^{-1}$ EDAC was added to the above suspension and the mixture was continuously stirred at room temperature for $45 \mathrm{~min}$. The suspension was filtered by a GVS membrane Nylon fil-ter, with 47 $\mathrm{mm}$ diameter and $0.45 \mu \mathrm{m}$ pore size. The solid material was rinsed thoroughly with deionized water to remove unreactedreagents.

\subsubsection{Imprinting step}

The modified CNT were redispersed in $1 \mathrm{ml}$ of $10 \mu \mathrm{mol} \mathrm{L}^{-1}$ PIPES buffer solution ( $\mathrm{pH} 7.0$ ) containing $8.0 \mu \mathrm{mol} \mathrm{L}^{-1} \mathrm{TnT}$ and

$0.1 \mathrm{~mol} \mathrm{~L}^{-1} \mathrm{NaCl}$ for $4 \mathrm{~h}$ at $4{ }^{\circ} \mathrm{C}$ to bind the template. The MWC- NTs were then incubated in $1 \mathrm{~mol} \mathrm{~L}^{-1}$ Tris for $30 \mathrm{~min}$ in order to 
Table 1

Membrane composition of TnT PVC membrane sensors and their analytical features in $1 \times 10^{-2} \mathrm{M} \mathrm{HEPES}$ buffer of pH 7.

\begin{tabular}{|c|c|c|c|c|c|c|c|c|c|}
\hline $\begin{array}{l}\text { Characteristic } \\
\text { lonophore }\end{array}$ & $\begin{array}{l}\text { ISE I } \\
M I / A a\end{array}$ & $\begin{array}{l}\text { ISE II } \\
\text { NI/Aa }\end{array}$ & $\begin{array}{l}\text { ISE III } \\
C N T / A a\end{array}$ & $\begin{array}{l}\text { ISE IV } \\
M I / T i\end{array}$ & $\begin{array}{l}\text { ISE V } \\
\mathrm{NI} / \mathrm{Ti}\end{array}$ & $\begin{array}{l}\text { ISE VI } \\
C N T / T i\end{array}$ & $\begin{array}{l}\text { ISE VII } \\
M I / A u\end{array}$ & $\begin{array}{l}\text { ISE VIII } \\
\text { NI/AU }\end{array}$ & $\begin{array}{l}\text { ISE IX } \\
\text { CNT/A }\end{array}$ \\
\hline $\begin{array}{l}\text { Slope/mV/D } \log ([T P N] / M) \\
r^{<}(n=2)\end{array}$ & $\begin{array}{l}53.7 \pm 1.6 \\
0.993\end{array}$ & $\begin{array}{l}-42.6 \\
0.941\end{array}$ & $\begin{array}{l}- \\
-\end{array}$ & $\begin{array}{l}38.3 \pm 5.3 \\
0.992\end{array}$ & $\begin{array}{l}- \\
-\end{array}$ & $\begin{array}{l}- \\
-\end{array}$ & $\begin{array}{l}49.6 \pm 0.3 \\
0.991\end{array}$ & $\begin{array}{l}45.9 \pm 7.1 \\
0.997\end{array}$ & - \\
\hline $\begin{array}{l}\mathrm{LOD} / \mu \mathrm{g} \mathrm{mL}^{-1} \\
\text { LLLR/M } \\
\text { Response time/s }\end{array}$ & $\begin{aligned} & 0.259 \\
& 9.0 \times 10^{-9} \\
< & 15\end{aligned}$ & $\begin{array}{l}0.304 \\
9.1 \times 10^{-9} \\
\text { Unstable }\end{array}$ & $\begin{array}{l}- \\
\overline{-} \\
\text { Unstable }\end{array}$ & $\begin{array}{l}0.435 \\
2.8 \times 10^{-8} \\
<15\end{array}$ & $\begin{array}{l}\overline{-} \\
\overline{-} \text { Unstâble }\end{array}$ & $\begin{array}{l}- \\
\overline{-} \\
\text { Unstable }\end{array}$ & $\begin{array}{l}0.157 \\
4.2 \times \\
<15\end{array}$ & $\begin{array}{l}0.234 \\
9.1 \times \\
<15\end{array}$ & $\begin{array}{l}- \\
<15\end{array}$ \\
\hline $\begin{array}{l}\mathrm{CV}(\mathrm{s} / \mathrm{mV}) \\
\text { Repeatability/mV (\%) }\end{array}$ & $\begin{array}{l}12.3 \\
13.2\end{array}$ & $\begin{array}{l}5.3 \\
12.4\end{array}$ & $\begin{array}{l}9.89 \\
36.8\end{array}$ & $\begin{array}{l}16.3 \\
26.1\end{array}$ & $\begin{array}{l}1.62 \\
1.4\end{array}$ & $\begin{array}{l}14.0 \\
14.0\end{array}$ & $\begin{array}{l}4.45 \\
5.1\end{array}$ & $\begin{array}{l}1.27 \\
1.75\end{array}$ & $\begin{array}{l}- \\
-\end{array}$ \\
\hline
\end{tabular}

LOD, limit of detection; LLLR, lower limit of linear range; CV, coefficient of variation.

block the un-reacted ester groups. Several washes with deion- ized water were followed and finally $1 \mathrm{ml}$ of $50 \mathrm{mmol} \mathrm{L}^{-1}$ AAM and 50 mmol L ${ }^{-1}$ NNMBA PIPES solution ( $\mathrm{pH} 7.0$ ) was added to the MWCNTs. After 60 min incubation, $1 \mathrm{ml}$ of $50 \mathrm{mmol} \mathrm{L}^{-1}$ APS solution in PIPES, $\mathrm{pH}$ 7.0, was added to start the polymerization. The polymerization was carried out at room temperature for $1 \mathrm{~h}$, after which the sensor was thoroughly washed with deionized water. Finally, $1 \mathrm{ml}$ of $1 \mathrm{~mol} \mathrm{~L}^{-1} \mathrm{Oac}$ was added to remove the tem- plate. This step was carried out at room temperature for $12 \mathrm{~h}$. The imprinted MWCNTs were washed and conditioned in $10 \mathrm{mM}$ phos- phate buffer, $\mathrm{pH}$ 8.0, in order to increase the $\mathrm{pH}$ and remove the peptide fractions produced by Oac treatment.

\subsection{SEM/EDC analysis}

SEM analysis was conducted over the dried $\mathrm{MI}, \mathrm{NI}$ and MWCNT materials, at room temperature and in low vacuum mode. EDC analysis was conducted on several sampling points for each biomaterial.

\subsection{FTIR analysis}

Infrared spectra were collected after background correction and under room temperature/humidity control. The number of scans was 32 for both sample and background. $X$-axis was wavenumber, ranging 525$4000 \mathrm{~cm}^{-1}$, and $Y$-axis was \% transmittance. Resolu-tion was 4000 .

\subsection{Preparation of sensory membranes}

About $100 \mathrm{mg}$ of PVC, $75 \mathrm{mg}$ of plasticizer (oNPOE) and $3.0 \mathrm{mg}$ of each sensing polymer MI-MWCNT, NI-MWCNT or MWCNT were mixed (see Table 1). The mixture was stirred until the PVC was well moistened, and dispersed in $3.5 \mathrm{~mL}$ THF. These membranes were

used to coat conductive wires of different metals and let dry during $48 \mathrm{~h}$. After drying, the electrodes were kept in $1 \times 10^{-4} \mathrm{~mol} \mathrm{~L}^{-1} \mathrm{TnT}$ solution.

\subsection{Potentiometric procedures}

Decreasing concentrations in TnT were obtained by transfer- ring 0.0200-1.0 mL aliquots of HEPES solution, $\mathrm{pH} 7.0$, to a $5.0 \mathrm{~mL}$ beaker containing $0.200 \mathrm{~mL}$ of $7.0 \times 10^{-8} \mathrm{~mol} \mathrm{~L}^{-1} \mathrm{TnT}$ solution pre- pared in HEPES buffer. The potential readings of the stirred TnT

solutions were measured at room temperature and recorded after stabilization to $\pm 0.2 \mathrm{mV}$.

The potential readings of the stirred $\mathrm{TnT}$ solutions were measured at room temperature and recorded after $10 \mathrm{~s}$ stabi- lization to $\pm 0.2 \mathrm{mV}$. Each calibration curve was done 3 times and followed IUPAC recommendations (Buck and Cosofret, 1993). Selectivity studies followed the Matched Potential Method (MPM) (Umezawa et al., 1995). The initial concentration of TnT was set to
$1 \times 10^{-7} \mathrm{~mol} \mathrm{~L}^{-1}$ and it was added of $4 \times 10^{-7} \mathrm{~mol} \mathrm{~L}^{-1} \mathrm{TnT}$, changing the potential in $10 \mathrm{mV}$. Solutions of interfering species were addeduntil the same potential change was observed. Synthetic serum was prepared and spiked with TnT. It was analyzed immediately without further preparation.

\section{Results anddiscussion}

\subsection{Design of plastic antibodies}

The plastic antibodies were designed by surface imprinting on MWCNTs in order to improve the number of effective binding sites. MWCNTs were selected because of its large surface area, recognized capacity to adsorb the template ( $\mathrm{TnT})$, and compatibility with a wide range of transducers.

The overall process for synthesizing the plastic antibody consisted on linking the protein to the surface of the CNT, filling the vacant places around it with a suitable rigid structure and remov- ing the protein after this (Fig. 1). Almost all steps were carried out under mild conditions to ensure that the protein $\mathrm{TnT}$ remained unaltered in terms of tridimensional distribution and electrostatic environment.

An overview of the reactions carried out for the covalent attachment of TnT to the MWCNTs is shown in Fig. 1A. The carboxylic acid groups on the surface of the MWCNTs were activated by EDAC. This reaction forms a highly reactive $O$-acylisourea inter- mediate (Jiang et al., 2004) that reacts quickly with NHS to form a more stable ester (succinimidyl intermediate). This ester undergoes nucleophilic substitution with any readily available amine group on TnT, resulting in the formation of an amide bond between the MWCNTs and TnT.

TnT-MWCNTs were then incubated in Tris solution for $30 \mathrm{~min}$ to block un-reacted ester groups. The resulting material was washed with PIPES solution ( $\mathrm{pH} 7.0)$ and let stand for 45 min first in AAM (vinyl monomer) and after in NNMBA (crosslinker), both prepared in the same buffer (see Fig. 1B). After an incubation period to allowthe orientation of monomers and cross-linkers around the tem- plate following electrostatic interactions, APS was added to start the polymerization. This polymerization was carried out at room temperature for $5 \mathrm{~h}$ to avoid any alterations of the protein confor-mation. The modified MWCNTs were washed again. The attached protein was after removed by reaction with Oac. Subsequently, the imprinted MWCNTs were washed 5 times, filtered and conditionedin $10 \mathrm{mM}$ phosphate buffer, $\mathrm{pH} 8.0$, for $1 \mathrm{~h}$. At this stage, the $\mathrm{pH}$ wasincreased from 1.2 to 8.0 to facilitate peptide/amino acid removal.

\subsection{SEM/TEM analysis}

The SEM images of the carboxylated MWCNT are shown in the first line of Fig. 2. The multi-walled tubes of carbon had an aver- age thickness of $12-13 \mathrm{~nm}$. This was confirmed by magnifying the original biomaterial by 400,000 and 800,000 times. As expected, 

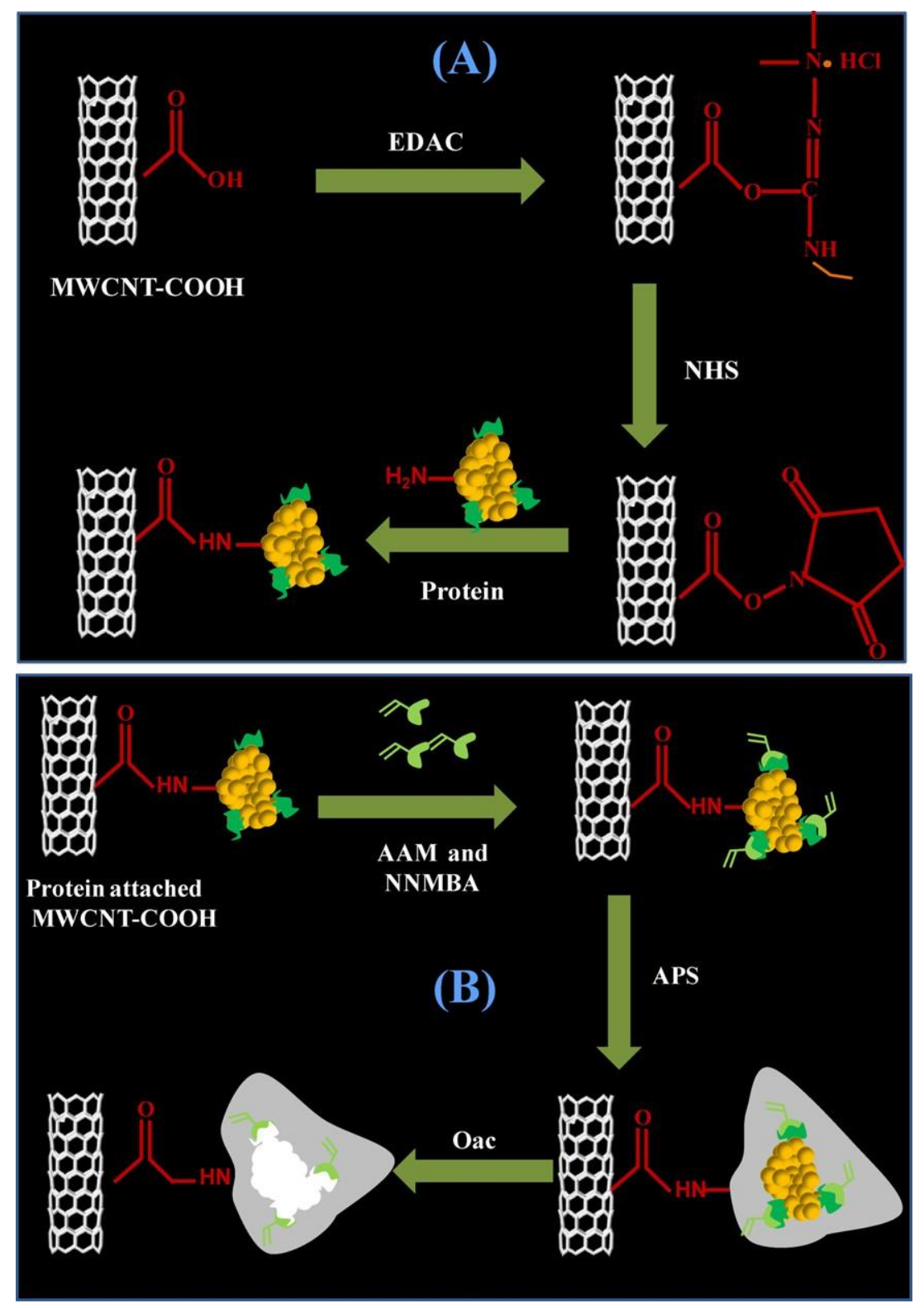

Fig. 1. MI of troponin T. Protein attach to carbon nanotubes via a two step process of diimide-actived amidation (A) and imprinting step with protein removal (B).

the EDS spectra confirmed the presence of $C$ and $O$, this last atom coming from the carboxyl functions.

The surface modification increased the thickness of the carbon rods

up to $15-19 \mathrm{~nm}$ (Fig. 2, second line). It also reduced signif- icantly the conductivity of the biomaterial. This was made clear by the poor resolution of the SEM image of MI-MWCNTs and NI- MWCNTs biomaterials obtained with 800,000 times magnification, especially when compared to those of the non-modified MWCNTs. The chemical modification of the MWCNTs introduced $\mathrm{Na}, \mathrm{S}$, and $\mathrm{Cl}$ in the overall structure (EDS spectra in Fig. 2). This was common in both MI-MWCNTs and NI-MWCNTs biomaterials. MI structures displayed, however, higher levels of these atoms, which probably resulted from prevailing peptide structures sequestered inside the imprinted layer.

The TEM images of the carboxylated MWCNT, MI-MWCNTs and NIMWCNTs are shown in Fig. 3. Although there was no protein label, several points of higher density were found on the wall of the CNTs. This has been attributed to protein structures bound to the tubes.

\subsection{FTIR analysis}

The spectra of non-modified and $\mathrm{MI} / \mathrm{NI}$ carboxylated MWCNTs are presented in Fig. 4. All bands come from the solid materials as an ATR accessory was used to collect the FTIR spectra and background was corrected previously. The carboxylated MWCNTs bear car- boxylic groups (useful to link proteins by their free amine groups), confirmed by the presence of a carbonyl function ( $\mathrm{C} \mathrm{O}$ ) by a strong absorption near $1650 \mathrm{~cm}^{-1}$. The strong absorbance observed at about $3300 \mathrm{~cm}^{-1}$ is also correlated to this functional group.

The surface modification of $\mathrm{MI}$ and $\mathrm{NI}$ materials presented in Fig. 2 resulted on the formation of several amide bonds. The car-boxylic group on the MWCNTs was changed to an amide and both monomer and cross-linker structures have this functionalgroup. Thus, $\mathrm{MI}$ and $\mathrm{NI}$ materials displayed a strong absorption band near $3400 \mathrm{~cm}^{-1}$, corresponding displacement to the let of about $100 \mathrm{~cm}^{-1}$ when compared to unmodified MWCNT. This band was assigned to $\mathrm{N}-\mathrm{H}$ stretching vibration. $\mathrm{C}-\mathrm{N}$ stretching vibra- tions could also be observed near 1300 and $1000 \mathrm{~cm}^{-1}$. The $\mathrm{C} \quad \mathrm{O}$ 


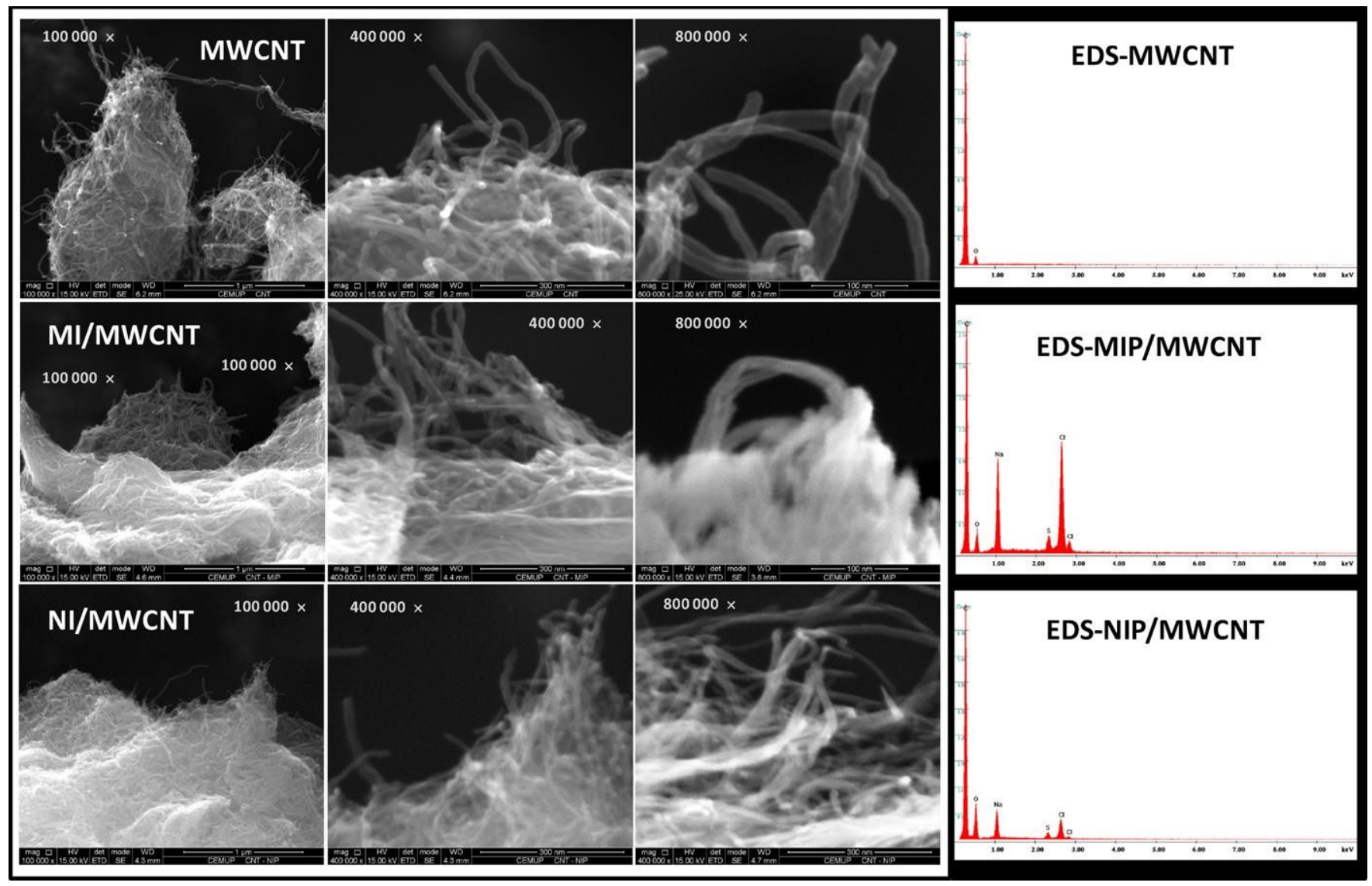

Fig. 2. SEM and EDC images of plain MWCNT (first line) and modified MWCNT by MI (second line) or by NI (third line) technologies.

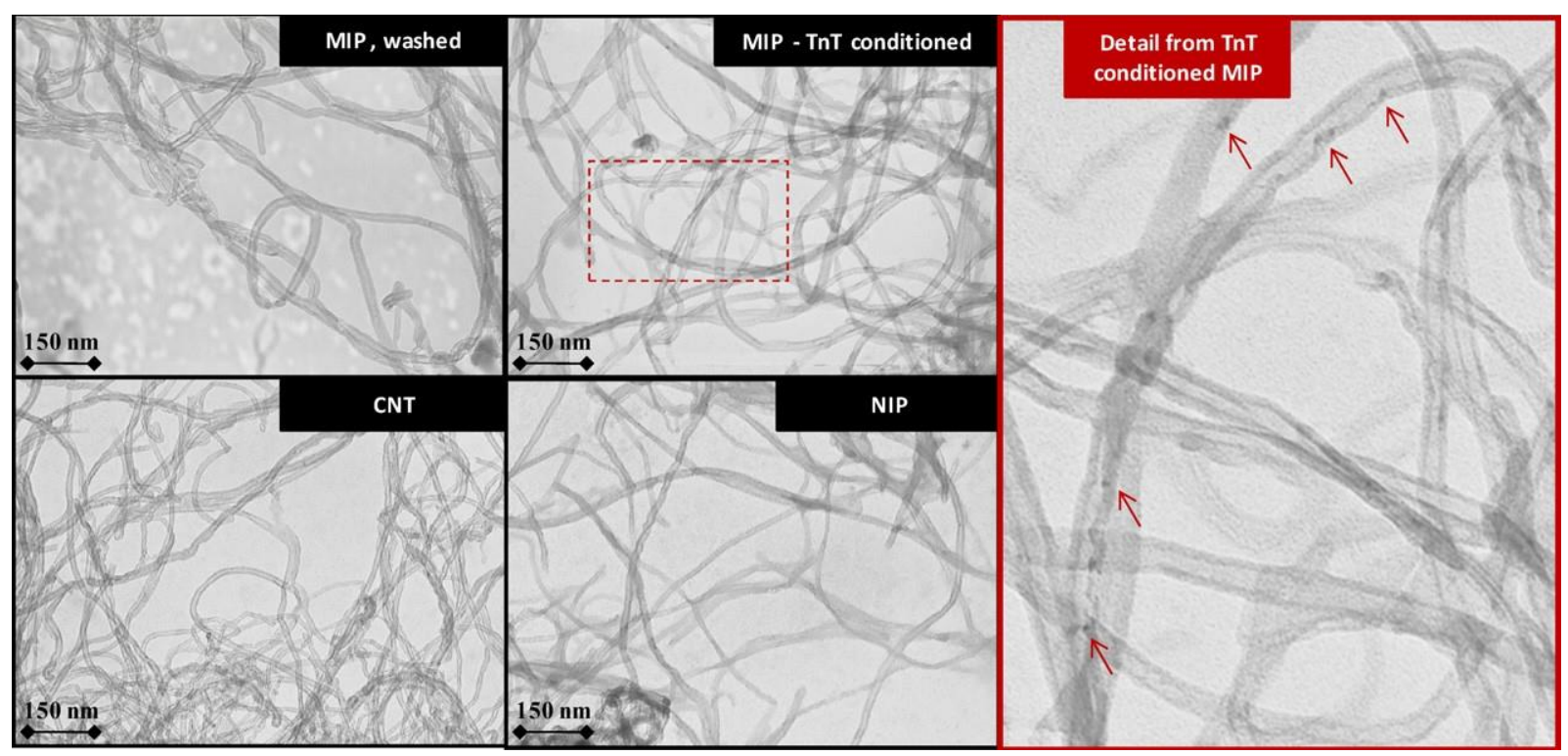

Fig. 3. TEM images of $\mathrm{MI}, \mathrm{NI}$ and $\mathrm{CNT}$ technologies.

group was mainly responsible for the strong adsorption around 1750 $\mathrm{cm}^{-1}$. Since there are no differences in terms of chemical com- position between $\mathrm{MI}$ and NI materials, their spectra look similar.

\subsection{Sensory surfaces}

The rebinding ability of the MI-MWCNTs and NI-MWCNTs was tested by using these materials as electroactive ingredi- ents. They were dispersed in a high dielectric constant plasticizer and PVC for this purpose. Non-modified MWCNTs were also employed as control. The obtained membrane was used to coat wires of different metals: silver, gold and titanium. This particu- lar configuration (coated-wire) was selected for allowing further miniaturization.

Their main analytical features were evaluated following the IUPAC recommendations (Buck and Lindner, 1994). Calibrations 


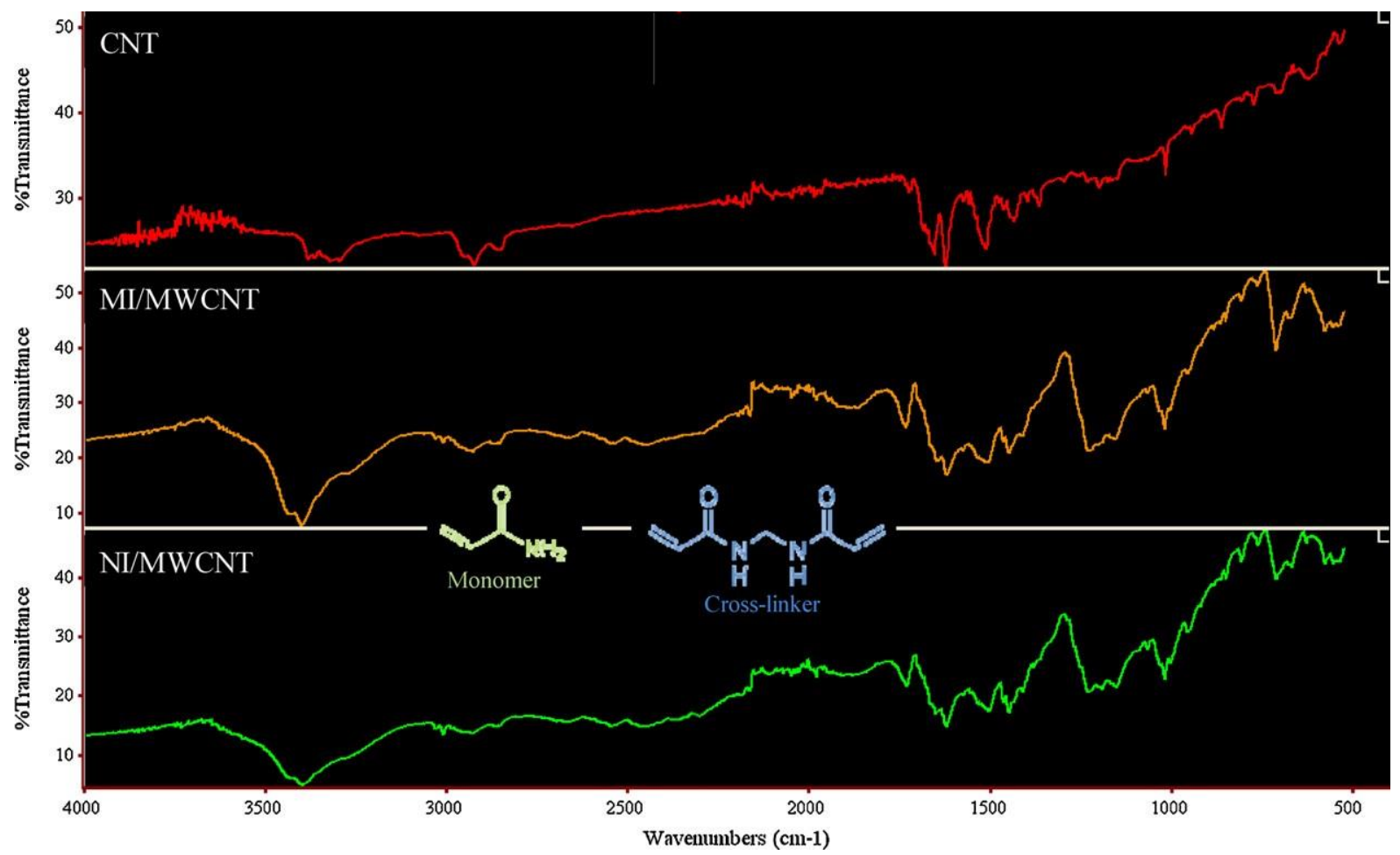

Fig. 4. FTIR images of plain MWCNT (first line) and modified MWCNT by MI (second line) or by NI (third line) technologies.

were initially made by increasing TnT concentrations. However, TnT reagent is very expensive and the amount spent in each cal- ibration is equivalent to $5.14 \mathrm{\mu g}$. To reduce the cost of this routine procedure, calibrations were made by decreasing the initial TnT concentration with buffer. Theamount of TnTrequired was reduced to $0.39 \mu \mathrm{g}$. For this purpose, indicating and reference electrodes

were dipped in $150 \mu \mathrm{L}$ of $7.0 \times 10^{-8} \mathrm{molL}^{-1} \mathrm{TnT}$ solution of fixed

$\mathrm{pH}$ and ionic strength. An eppendorf was used as "beaker" and the magnetic stirrer was $5 \mathrm{~mm}$ long. TnT concentrations were varied after by transferring $0.0200-1.000 \mathrm{~mL}$ aliquots of HEPES buffer, $\mathrm{pH} 7$, aqueous solutions. Potential readings were recorded after stabi- lization to \pm 0.2 $\mathrm{mV}$ and emf was plotted as a function of logarithm TnT concentration. Both calibration procedures were equivalent in terms of analytical features.

As a potentiometric sensor detects ionic species, the net charge of TnT in solution must be controlled. This feature is highly depen- dent on the $\mathrm{pH}$. The $\mathrm{pH}$ of its isoelectric point (8.8) ensures equal contribution of positive and negative charges and the net charge on the protein surface is zero, while in lower $\mathrm{pHs}$ the protein is predominantly positively charged (Labugger et al., 2003). In this work the pH selected was 7. It is near physiological conditions andensured positively charged species.

The analytical parameters of the calibrations are presented in Table 1 . The potential values of NI-MWCNT and MWCNT materi- als were found unstable in all concentrations tested. They showed however a consistent tendency to increase or decrease their potentials, in agreement with the results depicted in Fig. 5. However, as the protein is cationic under the tested $\mathrm{pH}$, only positive slopes may be attributed to a Nernstian behavior. This means that the negative changes occurred with the electrodes become from an unregulated and unpredicted performance that cannot be useful in terms of analytical application.

In general, the sensor with $\mathrm{Ml}$ as electroactive material showed the best analytical features (see Fig. 5). Linear behavior with $\mathrm{Ml}$ sensing polymer with coated-wire (silver, gold and titanium) electrodes was observed from $9.0 \times 10^{-9}, 4.2 \times 10^{-9}$ and $2.8 \times 10^{-8} \mathrm{~mol} \mathrm{~L}^{-1} \mathrm{TnT}$, cationic slopes were $53.7,49.6$ and $36.3 \mathrm{mV}$ decade $^{-1}$ and detection limits were $0.259,0.157$ and $0.435 \mu \mathrm{g} \mathrm{mL}^{-1}$ respectively. The gold-based electrodes displayed the lowest concentration for linear range, which is of utmost importance for a practical application of the proposed materials; their sensitivity was also suitable for this purpose. Gold is indeed the metal of choice for electrode devices; it is inert and displays excellent conductivity properties.

Using $\mathrm{NI}$ material as sensor, only silver and gold conductive supports displayed potential changes against TnT concentration. These were the most conductive and inert supports. The reported signals were however highly unstable. All potentiometric sensorsprepared with the corresponding MWCNTs particles (ISEs III, VI and

IX) displayed no linear response (see Fig. 5).

In principle, MI materials acted as charged ionophores because ISEs showed near-Nernstian responses without requiring a charged additive. Both electrostatic and stereochemical interac- tions between TnT and ionophore could be established for this purpose. $\mathrm{NI}$ polymers and CNT are limited to electrostatic interac- tions, because there is no spatial arrangement to carry the analyte. So, the observed slopes of NI-based ISEs outcome exclusively from these unspecific interactions. The difference to the slopes of MI- based ISEs, especially those based in $\mathrm{Ag}$ and $\mathrm{Ti}$ metals, is then probably correlated to the stereochemical recognition of TnT in the membrane.

These results indicated that the non-specific places of interac- tion (the only kind that exists on NI-MWCNTs or MWCNTs particles) between the template and the polymer were not mainly responsi- ble for the potentiometric response. Only monomers polymerized in the presence of a template may have imprinted cavities, enabling the specific interaction between the template and the sensor. Therefore, the potentiometric response observed for the $\mathrm{MI}$ elec-troactive materials is mainly due to a stereochemical recognition of the analyte at the imprinted cavities. 


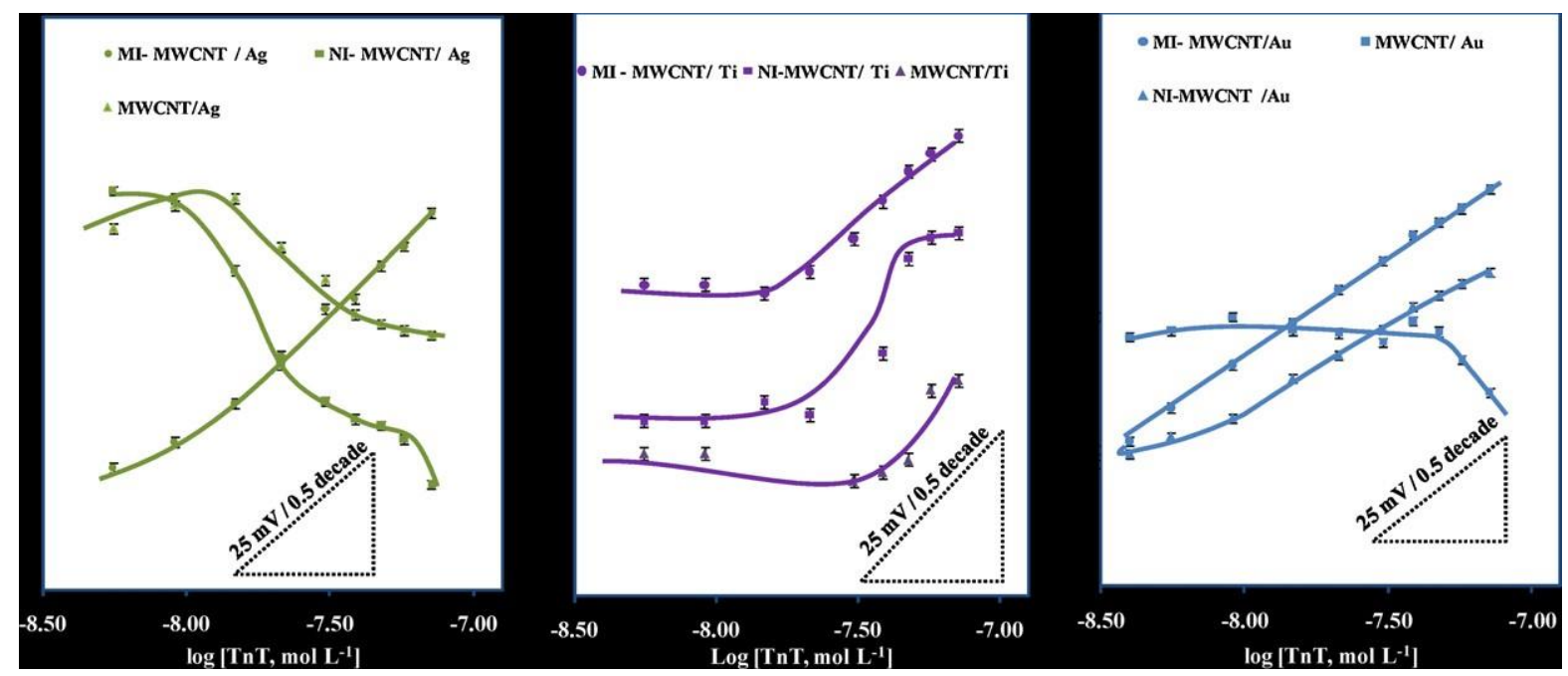

Fig. 5. Potentiometric response of the several TnT PVC membrane sensors under static mode of operation at $\mathrm{pH} 7$ with different coated-wire metals.

Table 2

Potentiometric selectivity coefficients were assessed by the matched potential method (MPM).

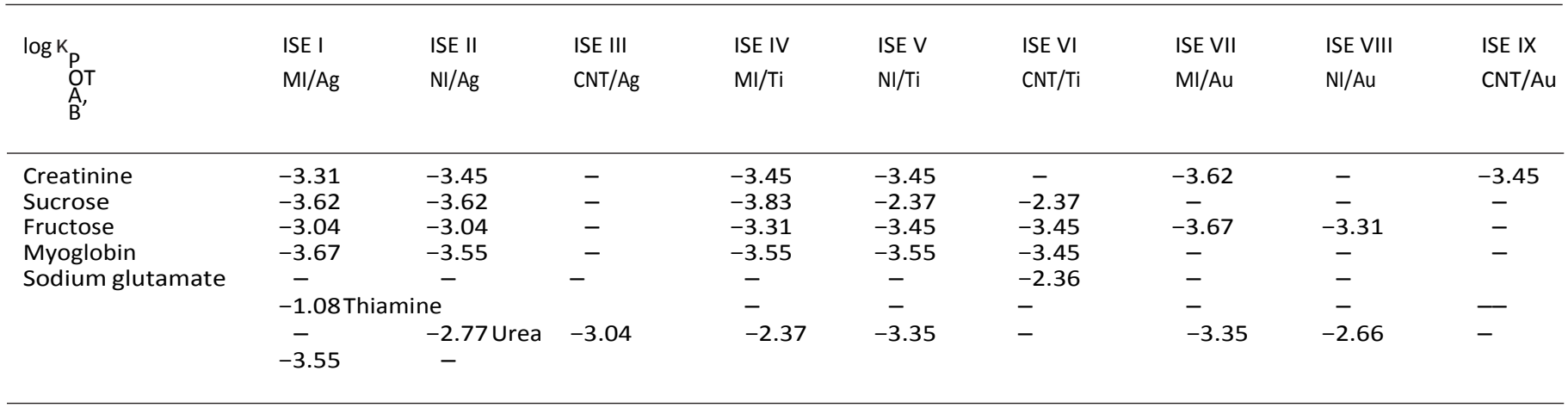

\subsection{Sensor selectivity}

The selectivity behavior of potentiometric sensor is defined by the ion exchange constants between electroactive biomaterial and TnT (Bakker and Pretsch, 2007). This suggests the use of ligands that strongly bind the preferred ion and only weakly all the others. Thus, the use of MIMWCNTs should induce a higher selectivity behavior, than both $\mathrm{NI}-$ MWCNTs and MWCNTs materials.

The selectivity behavior was assessed by calculating the potentiometric selectivity coefficients, $K_{A}^{P O}, B^{A s}$ the $K_{A}^{P O T}$, decreased, the sensor increased its preference for TnT. The matched potential method (MPM) was used for this purpose, as it is closer to a practical application of the sensor. It tests main and interfering ion together and does not require Nernstian behavior of the electrode against each interfering species (see Table 2). In this method, the poten- tiometric selectivity coefficient, calculated by Eq. (1), is defined as the activity (concentration) ratio of primary (A) and interfering (B) ions that give the same potential change under identical conditions

(Umezawa et al., 2000). At first, a known activity $\left(a A^{*}\right)$ of the primary ion solution is added into a reference solution that contains afixed activity $(a \mathrm{~A})$ of primary ion, and the corresponding potentialchange (IIE) is recorded. Next, a solution of an interfering ion is added $(a \mathrm{~B})$ to the reference solution $a \mathrm{~A}^{*}$ until the same potential change (IIE) is recorded.

$K A, B T=\frac{a A^{*}-a A}{a B}$

As possible interfering compounds, several organic species that are common in biological samples, such as proteins, sugars, aminoacids and metabolites, were selected. Creatinine, sucrose,
Almost all logarithm selectivity coefficients were below -3.0 (see Table 2). Below this limit any interference under study could have been a result of the dilution effect caused by the addition of the interfering ion, despite the use of highly concentrated interfering solutions. Only MWCNT and NI-MWCNT showed some logarithm selectivity coefficients above this limit, ranging from -2.77 to

-1.08 .

In many cases, the interfering species were unable to reach the potential change obtained by the main ion, as may be seen by the missing values in Table 2 . This may indicate very low interfering

effect, in the case of the electrodes that were working properly, or very small sensitivity, such as that observed for MI-MWCNT or MWCNT based membranes.

\subsection{Application}

The MI-based sensors were applied to determine TnT in syn- thetic serum samples ranging from 1.41 to $20.86 \mu \mathrm{g} \mathrm{mL}^{-1}$. A good agreement was found between added and found amounts of TnT. Results of the potentiometric analysis conducted in steady state showed recoveries ranging from 94.4 to $105.5 \%$ with an average relative standard deviation of $2.6 \%$. The relative error ranged from

-5.65 to $5.83 \%$ with an average relative standard deviation of $0.07 \%$.

\section{Conclusions}

fructose, myoglobin, sodium glutamate, alanine, thiamine and urea were considered for this purpose. Their interference was found negligible. 
Surface molecular imprinting technique was employed to produce biomimetic TnT tailored sensors for potentiometric trans-duction making use of host-guest interactions. Nanostructured materials were selected as support biomaterial to increase the number of imprinted sites. The results pointed out that membranesshould be casted over an Au wire for an improved performance. 
In general, the sensors offered the simplicity in designing, short measuring time, good precision, high accuracy, high analytical throughput, low limit of detection and good selectivity. As far as we know, there are no other chemical sensors for $\mathrm{TnT}$ in the litera-ture, and therefore the analytical performance of this work cannot be compared to other chemical-based methods. Only immunoas- says were developed and these display lower detection levels, but they are much more expensive, take much longer to reach a stable response and may suffer from irreproducibility by using compounds of biological origin.

Overall, the proposed method is simple, of low cost, pre- cise, accurate and inexpensive regarding reagent consumption and equipment involved. Further developments are required to enhance the specificity of the imprinted materials and decrease the LOD.

\section{Acknowledgement}

One of the authors (F.T.C.M.) gratefully acknowledges Fundação para a Ciência e Tecnologia for the financial support (PhD grant reference SFRH/BD/66735/2009).

\section{References}

Agasti, S.S., Rana, S., Park, M.H., Kim, C.K., You, C.C., Rotello, V.M., 2010. Adv. Drug Deliv. Rev. 62, 316-328.

Amemiya, S., 2007.In:Zoski, C.G. (Ed.), Handbook of Electochemistry. Elsevier (Chap- ter 7).

Bakker, E., Telting-Diaz, M., 2002. Anal. Chem. 74, 2781-2800.

Bakker, E., 2004. Anal. Chem. 76, 3285-3298.

Bakker, E., Qin, Y., 2006. Anal. Chem. 78, 3965-3983.

Bakker, E., Pretsch, E., 2007. Angew. Chem. Int. Ed. 46, 5660-5668. Bossi, A., Piletsky, S.A., Piletska, E.V., Righetti, P.G., Turner, A.P.F., 2001. Anal. Chem.

73, 5281-5286.
Bobacka, J., Ivaska, A., Lewenstam, A., 2008. Chem. Rev. 108, 329-351. Buck, R.P., Cosofret, V.V., 1993. Pure Appl. Chem.

65, 1849-1858.

Buck, R.P., Lindner, E., 1994. Pure Appl. Chem. 66, 2527-2536.

Cavaliere, C., Cucci, F., Guarino, C., Gubbiotti, R., Samperi, R., Lagana, A., 2008. Rapid Commun. Mass Spectrom. 22, 1159-1167.

Cummins, B., Auckland, M.L., Cummins, P., 1987. Am. Heart J. 113, 1333-1344. Dutra, R.F., Kubota, L.T., 2007. Clin. Chim. Acta 376, 114-120.

Dutra, R.F., Mendes, R.K., Silva, V.L., Kubota, L.T., 2007. J. Pharm. Biomed. Anal. 43, 1744-1750.

Eriksson, S., Wittfooth, S., Pettersson, K., 2006. Crit. Rev. Clin. Lab. Sci. 43, 427-495.

Guan, G., Liu, B., Wang, Z., Zhang, Z., 2008. Sensors 8, 8291-8320. http://www.medscape.com/viewarticle/463278 2 (accessed 28 August 2009).Jiang, K., Schadler, L.S., Siegel, R.W., Zhang, X., Zhang, H., Terrone, M., 2004. J. Mater.

Chem. 14, 37-39.

Kemp, M., Donovan, J., Higham, H., Hooper, J., 2004. Br. J. Anaesth. 93, 63-73. Katus, H.A., Remppis, A., Looser, S., Hallermeier, K., Scheffold, T., Kubler, W., 1989.

Mol. Cell. Cardiol. 21, 1349-1353.

Klein, G., Kampmann, M., Baum, H., 1998. Wien. Klin. Wochenschr. 3, 40-51. Labugger, R., Simpson, J.A., Quick, M., Brown, H.A., Collier, C.E., Neverova, I., Van Eyk, J.E., 2003. Clin. Chem. 49, 873-879.

May, A., Wang, T.J., 2008. Trends Mol. Med. 14, 261-267.

Merkoc, A., 2006. Microchim. Acta 152, 157-174.

McDonnell, B., Hearty, S., Leonard, P., Kennedy, R., 2009. Clin. Biochem. 42, 549-561.

Morrow, A., 2006. Cardiovascular Biomarkers, Pathophysiology and Disease Man-agement. Humana Press, Totowa, NJ.

Penttil, K., Koukkunen, H., Kemppainen, A., 1999. Int. J. Clin. Lab. Res. 29, 93-101.

Ramanaviciene, A., Ramanavicius, A., 2004. Biosens. Bioelectron. 20, 1076-1082. Risnik, V.V., Verin, A.D., Gusev, N.B., 1985. Biochem. J. 225, 549-552.

Simon, R., Collins, M.E., Spivak, D.A., 2007. Anal. Chim. Acta 591, 7-16. Takeuchi, T., Hishiya, T., 2008. Org. Biomol. Chem. 6, 2459-2467.

Thygesen, M.J., Katus, H., Plebani, M., Venge, P., Collinson, P., Lindahl, B., Giannitsis, E., Hasin, Y., Galvani, M., Tubaro, M., Alpert, J.S., Biasucci, L.M., Koenig, W., Mueller, C., Huber, K., Hamm, C., Jaffe, A.S., 2010. Eur. Heart J. 31, 2197-2204.

Turner, N.W., Jeans, C.W., Brain, K.R., Allender, C.J., Hlady, V.H., Britt, D.W., 2006.

Biotechnol. Prog. 22, 1474-1489.

Umezawa, Y., Umezawa, K., Sat, H., 1995. Pure Appl. Chem. 67, 507-518. Umezawa, Y., Bühlmann, P., Umezawa, K., Tohda, K., Amemiyap, S., 2000. Pure Appl.

Chem. 72, 1851-2082. 